This item was submitted to Loughborough's Research Repository by the author.

Items in Figshare are protected by copyright, with all rights reserved, unless otherwise indicated.

\title{
Assessing the impact of libraries - the role of ISO 16439
}

PLEASE CITE THE PUBLISHED VERSION

https://doi.org/10.1108/ILS-05-2017-0037

PUBLISHER

Emerald

VERSION

AM (Accepted Manuscript)

\section{PUBLISHER STATEMENT}

This work is made available according to the conditions of the Creative Commons Attribution-NonCommercialNoDerivatives 4.0 International (CC BY-NC-ND 4.0) licence. Full details of this licence are available at: https://creativecommons.org/licenses/by-nc-nd/4.0/

\section{LICENCE}

CC BY-NC-ND 4.0

\section{REPOSITORY RECORD}

Creaser, Claire. 2019. "Assessing the Impact of Libraries - the Role of ISO 16439". figshare. https://hdl.handle.net/2134/27407. 
Assessing the impact of libraries - the role of ISO 16439

\begin{tabular}{|r|l|}
\hline Journal: & Information and Learning Science \\
\hline Manuscript ID & ILS-05-2017-0037.R1 \\
\hline Manuscript Type: & Article \\
\hline Keywords: & Impact, ISO 16439, Methods, library, measurement, standards \\
\hline \multicolumn{2}{|l}{} \\
\hline
\end{tabular}

SCHOLARONE ${ }^{\text {m }}$

Manuscripts 


\section{Assessing the impact of libraries - the role of ISO 16439}

\section{Abstract}

\section{Purpose}

Library impact and how to evaluate it has been debated for a number of years. While the activity - the busy-ness - of the library is now routinely measured and described, the difference the library makes is less tangible and harder to measure. Libraries in all sectors and worldwide are grappling with this issue.

\section{Design/methodology/approach}

The first international standard concerning library impact, ISO 16439 Information and documentation - Methods and procedures for assessing the impact of libraries, was published in 2014 after several years in development.

\section{Findings}

The standard describes a range of methods for assessing library impact which have been used across the world in a variety of libraries in all sectors.

\section{Originality/value}

This paper summarises the key methods described in the standard, and gives references for further reading.

\section{Keywords}

Impact; ISO 16439; Methods; library; measurement; standards

\section{Introduction}

Library performance has been measured and assessed by means of the resources put into the service and the use made of those resources for many years. Evaluation also routinely extends to measures of customer satisfaction. Whilst valuable in terms of running an efficient and cost-effective service, library statistics do not answer the fundamental question, increasingly asked by both librarians and other stakeholders - what difference does the library service make to an individual or a community? As a result, librarians and information scientists have begun to develop ways of measuring the impact of library services.

Library impact is not an exact science. It might be thought that something intangible and difficult to measure is not a proper subject for ISO standards, which are generally very precise in their specifications. From about 2000, library impact has gained increasing importance as publically funded organisations have come under ever greater scrutiny to demonstrate their value to stakeholders and justify their funding. Covey (2002) described the state of academic library performance measurement at that time as 'often ineffective and inefficient' (p156). She also noted increasing demands for accountability on the part of 
both governments and institutions. Library assessment has moved on, and is now embedded in practice, but the demands for accountability have grown, and there has been an increasing appreciation that the more easily measured concepts of inputs and outputs resources and activities - while remaining necessary, are no longer deemed sufficient to measure library performance and value. ISO 16439 was developed in response to a perceived demand for guidance on effective methods of assessing impact in libraries of all types across the world.

An international committee of experts, including the author of this summary, collaborated to produce the standard, which describes a wide variety of methods and techniques, all of which have been tested in libraries and found to be reliable methods of assessing library impact. The process began in 2010, and the first edition of the standard was published in 2014. The committee - known as ISO TC 46/SC 8/WG10 - continues to collect relevant new material for future editions of the standard, which will be formally reviewed in 2019.

ISO 16439 comprises ten chapters, covering the scope of the standard, and giving normative references and defining key terms used, before moving on to a detailed definition and description of library impact. Methods for assessing impact are separated into those using inferred evidence, solicited evidence and observed evidence, and ways of combining methods are described. The economic impact of libraries is considered separately. A series of annexes give examples of impact survey questions suitable for a range of circumstances, points to take into account when choosing a method, and describing how library impact assessment fits within broader institutional assessment practices.

This paper summarises the main sections of the standard, focussing in particular on those aspects and methods which are applicable to libraries in higher education.

\section{What is library impact?}

When considering library performance, a number of terms are commonly used to describe the basic elements for measurement:

- Input - the resources provided to the service (e.g. stock, staffing, premises, finance)

- Output - the use made of the service (e.g. loans, downloads, visits)

- Outcome - the effect of the outputs, in relation to the service's goals and objectives (e.g. user satisfaction)

- Impact - the difference the library service makes to individuals and/or society (e.g. qualifications gained, economic impact)

- Value - the importance stakeholders attach to the library service (e.g. contribution to culture, student recruitment)

Library processes transform inputs into outputs, which lead to outcomes, and all of these are routinely measured by libraries of all sectors. Impact is less tangible, and value - other than in the sense of economic value for money - even more so. Measuring these aspects of 
library performance is becoming increasingly important, as libraries compete within their parent institutions for limited resources.

ISO 16439 notes that library impact can have many aspects. It can be immediate, such as finding the required reference for an essay, or long-term, for example improvements in information literacy. It may be limited, with a small increment in skills, or far-reaching, changing someone's life. It is generally thought of as positive, but a bad library experience can have a negative impact, discouraging repeated use. Types and effects of impact will also differ according to who or what is being impacted - individual users; the parent institution; or wider society, for example.

For individual library users, the resources and services provided by the library service may result in improved skills or competencies, changes in attitudes or behaviours, greater academic or career success, or improved wellbeing, for example. For an academic institution, the library can contribute to prestige and reputation, increased institutional funding for research and can help to attract high quality staff and students.

It is also important to note that different elements of the library service may have different impacts on users, and elements may have different impacts on different stakeholders. Comprehensive collections based around reading lists can be expected to have an impact on student assignments and attainment, while journal collections may have more relevance to researchers, with potential impacts in the area of $\mathrm{PhD}$ completions and successful funding applications - potentially impacting on the institution more widely. A leisure reading collection may have an impact on the health and well-being of both staff and students. These separate impacts can all be measured - what is more difficult is to describe a single, overarching impact for the service as a whole.

\section{Methods for assessing library impact}

Because library impact is relatively intangible, assessing it presents a number of challenges. It is a more demanding process than counting inputs and outputs, and takes considerable time and effort. For anything other than short-term, immediate, impact, longitudinal studies are needed. Further, the library will not be the only factor in any given impact, and isolating its contribution is not always straightforward.

Library impacts generally cannot be measured directly, and surrogate or proxy measures are required. Evidence of impact can be inferred, through output data, performance indicators or user satisfaction, for example. It can also be solicited by consulting users, or it can be observed (Streatfield, 2002). The techniques used are not new, nor are they unique to impact measurement, but draw on the range of research methodologies employed throughout the social sciences. This section of the paper summarises the various techniques and types of impact evidence included in ISO16349. 


\section{Inferred evidence}

Chapter 6 deals with inferred evidence of impact. Library statistics are routinely collected and monitored; they do not, of themselves, measure library impact, but can be used to point to library impact. For example, changes in users' behaviour and skill levels can be demonstrated by time series data on usage, or data showing how the profile of users has changed. Increasing levels of use might suggest that users are finding the services they use beneficial; similarly, increased participation from one segment of the population may suggest that services for that target group are relevant and well-received. Times series of performance indicators can be used in a similar way. For example, increased attendance at user training sessions may suggest that users gain benefit from the sessions.

User satisfaction is not synonymous with impact. It is possible for a user to be completely satisfied with a service which has had no impact at all. However, high levels of satisfaction with some services in particular are likely to be linked to the benefits gained from those services. For example, high levels of satisfaction with user training are likely to be linked with the acquisition of relevant skills.

Note that data from sources other than the library can contribute to the evidence base. Of particular relevance to academic libraries is data on student attainment, although this can be fraught with ethical issues, and the library is not the only influence on student attainment.

It is important to note that such evidence cannot stand alone to demonstrate impact, but must be supported by other methods.

\section{Solicited evidence}

Chapter 7 of ISO 16439 describes solicited evidence, which is obtained directly from users, generally by means of a questionnaire survey, although other methods such as interviews or focus groups are sometimes used. Questions about the impact of using the library service can be the focus of the questionnaire, or may be inserted into a broader instrument seeking information about library use and/or satisfaction, for example. Questionnaires relating to a particular activity can be distributed at the time, or, if a record of attendance is kept, some time later - for example, have you found the information provided in the session useful for your studies? An alternative approach puts questions in the context of what users might have done had the library service not been available to them.

Interviews and focus groups allow for more in-depth investigation of issues, and teasing out the detail of library impact. They can also deal with more general questions - what is the major benefit to you when using the library? Such methods are resource intensive, but generate a wealth of qualitative data on the impact of the library across a range of activities. Case studies are not widely used to provide evidence of impact, but can be an additional source of in-depth data, if sufficient resources are available to support them. 
More informal anecdotal evidence can also be obtained, from personal experiences contributed by users or staff. Such evidence is not collected systematically, nor is it empirically tested, so it cannot be considered to be scientifically sound, but it has value in pointing out areas of potential impact for further investigation, and for illustrating the results of other methods.

\section{Observed evidence}

Chapter 8 covers a variety of methods for gathering evidence by observation, including observation of users by researchers or remotely via video-recording or log analysis, as well as self-recording by users, and analysis of the citations made in written assignments.

Observation can be structured or unstructured, carried out openly with the knowledge of the observed person, or covertly, with the observer participating in activities or watching from the side-lines. As with other methods, evidence of impact can be obtained by collecting data before and after a library intervention, identifying changes in behaviour, skills or attitudes.

Self recording by users is included as an important tool, allowing the collection of longitudinal data with minimal cost. Such evidence is generated by asking users to keep a diary recording their behaviours or attitudes in a particular area over a period of time. These diaries are then analysed for changes in patterns of use in relation to interactions with library services.

A further type of observed evidence, of particular relevance to academic libraries, can be obtained by testing the knowledge, competencies and skills of library users, and is a wellestablished practice, particularly in the US. Response rates are generally high, and the results are clear and unambiguous. Such tests can be used to indicate impact when used before and after instruction, where significant improvements in performance indicate the impact of the course.

Citations in student papers or doctoral theses can also be used to assess the library's impact on the information literacy of students (Tuñon \& Brydges, 2005). The extent to which scholarly sources are used, and cited appropriately, demonstrates the effectiveness of information skills training, particularly when groups receiving different levels of training are compared, or evaluating work before and after training (Hurst \& Leonard, 2007).

\section{Combining methods - some examples}

Many of the methods described in detail in ISO 16439 are most effective in demonstrating impact when used in combination, and this aspect is covered in Chapter 9, with a number of examples being provided. They may be purely quantitative - for example comparing library use data with institutional data to identify statistical relationships between library use and performance. They may be qualitative, for example examining relationships between actions and outcomes. They may combine both, integrating student test results with 
interview findings and self-assessment, for example. Qualitative methods also add context and depth to quantitative data, to identify and illustrate impacts.

One area in which methods have been combined to demonstrate impact is that of student attainment. A number of studies have been carried out comparing library usage with student assessment data:

- In Australia, Cox \& Jantti (2012) have shown that increased use of the library's electronic resources is associated with better student performance

- In the UK, Stone et al. (2011) showed a correlation between library use and student attainment. Subsequent work confirmed these results across eight universities (Stone \& Ramsden 2014), although the authors stress that correlation does not imply causation.

- In the USA, Bowles-Terry (2012) found that students who had received information literacy instruction achieved better academic results than those who had not, supported by qualitative findings from focus groups.

Academic libraries have also been shown to have other impacts. One US study found a positive correlation between the use of library resources and successful grant applications, for example (Tenopir et al., 2010).

\section{Assessing the economic value of libraries}

The final section of the standard (Chapter 10) deals with the slightly different topic of assessing the economic value of libraries. This uses rather different methods, which may be less familiar to library and information professionals. There are two broad approaches which are described - identifying the monetary value of library services to users, and identifying the broader influence of the library on the economic life of the community, region, or national economy. The first of these may be more relevant to academic libraries, particularly if that value can be shown to be greater than the level of the institutional investment in the library.

The standard recognises that identifying the monetary value of library services is not a trivial task, noting that it can be accomplished in several ways, which, in practice, may need to be combined to give a complete picture. For services which are available commercially, a replacement cost can be calculated - for example the cost of purchasing a book or journal article as replacement for a loan or download. Establishing a surrogate price for other services is less clear, however. The monetary value of the service can be estimated by multiplying the unit cost of each service used by the number of uses of that service.

A second method described is based on the premise that the value of the library service must be at least equal to the value the user places on the time and effort required to use the service. This is perhaps less relevant to academic libraries, where students at least are not salaried so that costing their time is not possible. 
Asking users what they think the library service is worth is a third option described, but it is noted that this is very subjective. It is most formally expressed as contingent valuation, which is an economic method to estimate the benefits of a non-priced service by considering what would happen if it were not available. It has been most frequently used in the public library sector, where questions of value can be put in terms of higher or lower taxation, although perhaps the best known example is a study by the British Library, concluding that for every $£ 1$ spent on the library, more than $£ 4$ of value was generated (Pung et al., 2004).

\section{Choosing a method}

As with all research - and measuring the impact of your library is essentially research - the methods you choose will depend on the questions you seek to answer. This aspect is covered in an annex to the main standard (Annex B). Impact studies must start with determining which area of possible impact is to be investigated, and what kinds of data are required to demonstrate that impact. The methods, and scope of the study, will also depend on the resources and expertise available to carry it out.

Changes in skills and competencies are frequently identified by tests, but other methods such as observation or solicited evidence can also be used. Changes in attitudes and behaviours can be demonstrated by surveys, interviews or focus groups, and can be corroborated by data on library use. Academic success is measured by coursework marks or degree level, and may require the cooperation of institutional administrators to associate this with library use without breaching confidentiality. In all cases, a combination of qualitative and quantitative methods can provide the most convincing evidence.

\section{Conclusion}

In order to assess the impact of library services, it is helpful to break down the process into its component parts. Firstly, consider the areas of the service for which you want to identify an impact. This may be something focussed, such as information literacy training, or more general, such as resource provision.

Secondly, focus on what impacts you might expect those areas of the service to have, and on whom. In the example of information literacy training, the expected impact would be increased skills; for resource provision, one impact may be improved student performance.

Thirdly, consider what might indicate that those impacts have been achieved - the evidence you need to demonstrate the impact. Improved information literacy skills might be shown by more appropriate use of sources, or better referencing, for example.

The next step is to identify and define the measures you need to collect to provide that evidence, and where the data might be obtained. These could include data from beyond the library, particularly when it comes to student attainment. Other data will come from library sources; some will need to be collected specifically for the purpose. It is only at this stage 
that the measures described in ISO16489 can be brought into the process, providing a set of standardised methods and examples of surveys which can be used.

\section{References}

Bowles-Terry, M. (2012) "Library Instruction and Academic Success: A Mixed-Methods Assessment of a Library Instruction Program", Evidence Based Library and Information Practice, 7(1) pp 82-95

Covey, D.T. (2002) “Academic Library Assessment: New Duties and Dilemmas", New Library World 103(1175/1176) pp 156-164

Hurst, S. \& Leonard, J. (2007) “Garbage In, Garbage Out: The Effect of Library Instruction on the Quality of Students' Term Papers", Electronic Journal of Academic and Special Librarianship 8(1). Available at http://southernlibrarianship.icaap.org/content/v08n01/hurst_s01.htm (accessed 20-0417)

International Standards Organisation (2014) ISO 16439 Information and documentation Methods and procedures for assessing the impact of libraries, Switzerland: Geneva

Pung C., Clarke, A. \& Patten, L. (2004) "Measuring the economic impact of the British library", New Review of Academic Librarianship, 10(1), pp79-102

Stone, G., Pattern, D. and Ramsden, B. (2012) "Library Impact Data Project: hit, miss or maybe". in: Proving value in challenging times: proceedings of the 9th Northumbria international conference on performance measurement in libraries and information services. August 22-25, 2011 University of York, York. pp. 385-390.

Stone, Graham and Ramsden, Bryony (2013) "Library Impact Data Project: looking for the link between library usage and student attainment". College and Research Libraries, 74 (6). pp. 546-559.

Streatfield, D. (2002) "Getting at the impact of services", in Brewer, S. (ed.) Value and Impact Studies: Getting the Benefit: Proceedings of a Seminar held at Stamford, Lincolnshire on 24 April 2002, Capital Planning Information Ltd, pp 37-42

Tenopir, C., King, D.W., Mays, R., Wu, L. \& Baer, A (2010) “Measuring value and return on investment of academic libraries" Serials 23(3), pp 182-190

Tuñon, J. \& Brydges, B. (2005) "Improving the quality of university libraries through citation mining and analysis using two new dissertation bibliometric assessment tools", in Proceedings of the World Library and Information Congress: 71st IFLA General Conference and Council August 14th - 18th 2005, Oslo, Norway. Available at https://archive.ifla.org/IV/ifla71/papers/078e-Tunon_Brydges.pdf (accessed 20-04-17) 